\title{
ONLINE OPERATIONAL EARLY WARNING SYSTEM PROTOTYPES TO FORECAST COASTAL STORM IMPACTS (CEWS)
}

\author{
Piet Haerens ${ }^{1}$, Paolo Ciavola ${ }^{2}$, Óscar Ferreira ${ }^{3}$, Ap van Dongeren ${ }^{4}$, Mark Van Koningsveld ${ }^{5}$, \\ Annelies Bolle ${ }^{6}$ \\ Extreme coastal storms have a destructive impact on coastal areas and directly affect people living in the coastal zone, \\ being this emphasized by recent events (e.g. Katrina, Xynthia) which reminded the world of the vulnerability of \\ coastal areas. The economic constraints and the increasing vulnerability of coastal areas (due to sea level rise and to \\ increased occupation) make it impossible to continue with a coastal zone management strategy based solely on \\ engineering schemes to protect vulnerable coastal areas across Europe. Development tools and methods that improve \\ today's forecasting, prediction and early warning capabilities in order to improve the assessment of coastal \\ vulnerability and risks are strongly needed and should be part of future prevention, mitigation and preparedness \\ measures. Within the MICORE project online operational storm early warning systems (CEWSs) using open-source \\ models and tools for reliable predictions of the morphological impact of marine storm events were developed and \\ demonstrated. The system makes use of existing off-the-shelf models as well as a state of the art open-source \\ morphological model (XBeach). The project specifically targeted the development of early warning and information \\ systems to support a short term emergency response in case of an extreme storm event (CEWS). The current paper \\ describes the applied system architecture, the model set-up and the storm impact indicator (SII) oriented approach. It \\ also highlights the need for further developments and application.
}

Keywords: coastal storms, morphodynamic feedback loop, early warning systems.

\section{INTRODUCTION}

Recent extreme hydro-meteorological events in coastal areas have highlighted the devastating effects from hazards of marine origin. The experiences of Hurricane Katrina that struck the city of New Orleans as well as the Xynthia storm in Europe demonstrated what can go wrong when engineering design or coastal protection is subjected to forcing beyond its design limits and civil evacuation and management plans fail. The 1953 storm surge event in the North Sea that resulted in over 2000 deaths and extensive flooding across The Netherlands, England, Belgium and Scotland is also a pertinent reminder that Europe is not immune to coastal threats. With approximately $185000 \mathrm{~km}$ of coastline, Europe encompasses a diverse range of coastal environments, including pristine natural habitats, large coastal cities protected by offshore structures, low-lying sandy dune fields, steep rocky cliffs, exposed oceanic coastlines and enclosed sea basins. Each coastal type presents a unique set of issues for coastal managers to deal with.

Taking into consideration the increased human occupation at coastal areas, the expected sea level rise and the existing economic constrains it is necessary to look for sustainable civil protection schemes based on innovative tools and methods in order to protect the vulnerable coastal areas across Europe against today's and tomorrow's extreme marine events. In a rapidly-changing global climate there is a considerable degree of uncertainty as to how extreme events will behave in the future, particularly with regard to the intensity, magnitude and duration of coastal storms. Hence there is a pressing need to develop new coastal management systems; ones that can accommodate this uncertainty and minimise the impacts of extreme conditions that fall outside the design limits of both current and future coastal structures.

In this context, the ability to predict the imminent arrival of coastal threats is a valuable tool for civil protection agencies in order to prepare themselves and, if needed, execute the appropriate hazardreduction measures. Developments in climate modelling have resulted in coastal storm predictions of a high level of sophistication, allowing to predict quite precisely their timing, intensity and other important storm variables up to approximately three days in advance. Building further on this is a way of knowing and communicating in real-time how these storm forcing predictions translate to morphological impacts and risk scenarios in the coastal zone.

\footnotetext{
${ }_{1}^{1}$ International Marine and Dredging Consultants, Coveliersstraat 15, Antwerp, 2600, Belgium.

${ }^{2}$ Dipartimento di Scienze dell Terra, University of Ferrara, Via Saragat 1, Ferrara, 44122, Italy.

${ }^{3}$ CIMA, Centre for Marine \& Environmental Research, University of the Algarve, Campus de Gambelas, Faro, 8005139, Portugal.

${ }^{4}$ Marine and Coastal Systems, Deltares, PO Box 177, Delft, 2600MH, The Netherlands.

${ }^{5}$ Civil Engineering and Geosciences, Delft University of Technology, PO-Box 5048, GA-Delft, 2600, The Netherlands.

${ }^{6}$ International Marine and Dredging Consultants, Coveliersstraat 15, Antwerp, 2600, Belgium.
} 
At present most of the European forecasting effort is related to the forecasting of physical parameters, like wave heights, water levels or wind speeds. Seldom are these parameters combined to predict the impact of their mutual effect on the coastal zone, leading to coastal hazards like overtopping, overwashing, beach and dune erosion, dune breach and flooding which are an effect of combined hydro-meteorological forces. The lack of prediction of the combined effect results in incomplete forecasts of the impact of marine events and is insufficient to support adequate risk mitigation, preparedness and awareness actions. The accurate definition of storm thresholds above which important morphological changes or damages to man-made structures occur is not consistently described in the scientific literature. It is often merely described as a wave height limit above which it is considered that a storm occurs, with or without causing damage or important morphological changes (Ciavola et al. 2011a). MICORE Project brought advancement to the understanding of morphological changes induced by storms by developing high-quality and innovative process-based modelling CEWSs. Within the EU-FP7 MICORE project prototypes of CEWSs have been developed for 9 test cases illustrated in Figure 1.

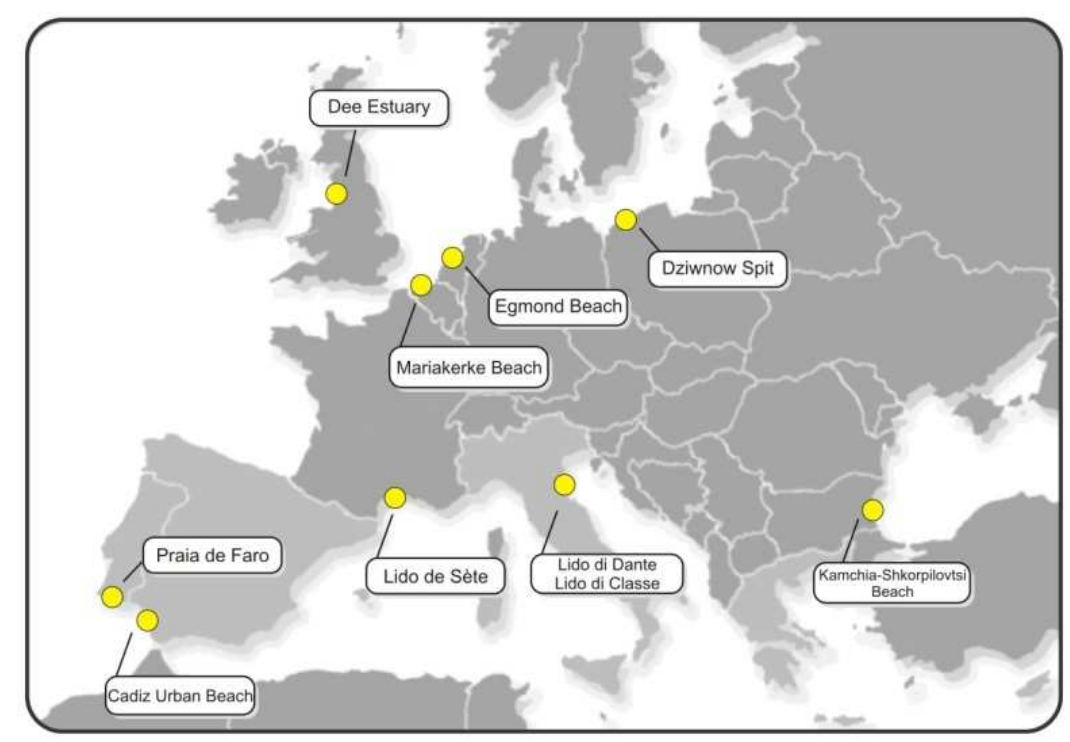

Figure 1 - Test sites for which the on-line operational CEWS prototypes have been set up.

\section{ARCHITECTURE OF THE STORM IMPACT EARLY WARNING SYSTEM (CEWS)}

Early warning systems are defined as operational tools that provide timely and effective information, through identified institutions, allowing to take actions to avoid or reduce the risk and increase the preparedness of individuals exposed to a hazard (United Nations - UNISDR 2006). EWSs are already successfully operational for river flooding, tsunami occurrences, hurricanes, but not yet widely used for coastal hazards. The objective of any people-centred early warning system is to empower individuals and communities threatened by hazards to act in sufficient time and in an appropriate manner so as to reduce the possibility of personal injury, loss of life, damage to property and the environment and loss of livelihoods (United Nations - UNISDR 2006).

A complete and effective EWS should comprise at least four inter-related elements: risk knowledge, monitoring and warning service, dissemination and communication and response capability. These elements are translated into a generic structure for an EWS of coastal risk (see Figure 1) which was developed and demonstrated at nine different test sites in Europe. In general the set-up of an EWS to forecast the impact of an upcoming marine event consists of the following essential steps, i.e. model set-up, data collection, pre-processing, running model engines, post-processing and visualisation (Baart et al. 2009 and Ciavola et al. 2011b). In line with this the applied prototype CEWS structure is based on five essential modules: (i) an observation module, where weather, wave, surge and initial beach profile measurements necessary for numerical modelling are collected, (ii) a forecast module (e.g. XBeach), having as input the observation module and as output the forecast of the morphological changes and consequences (iii) a decision support module, containing tools (i.e. Storm Impact Indicators) and results (e.g. hazard maps) to assist decision making, (iv) a warning module, where warnings are issued according to various site-specific thresholds and ( $\mathrm{v}$ ) a visualisation module, displaying on-line information to assist end-users. 
In order to convert predicted weather forecasts (i.e. wind and pressure fields) into a wave field and/or a surge level and finally into appropriate warnings for coastal managers, a number of numerical models should be combined in the forecast module. An integral part of a CEWS is the morphological (coastal erosion and over-toping/over-wash) forecast module, integrating the morphological feedback loop. As shown in the diagram in Figure 2, this module translates forecasts of offshore forcing parameters (e.g. surge and wave forecasts) into information about storm impacts in the coastal zone.

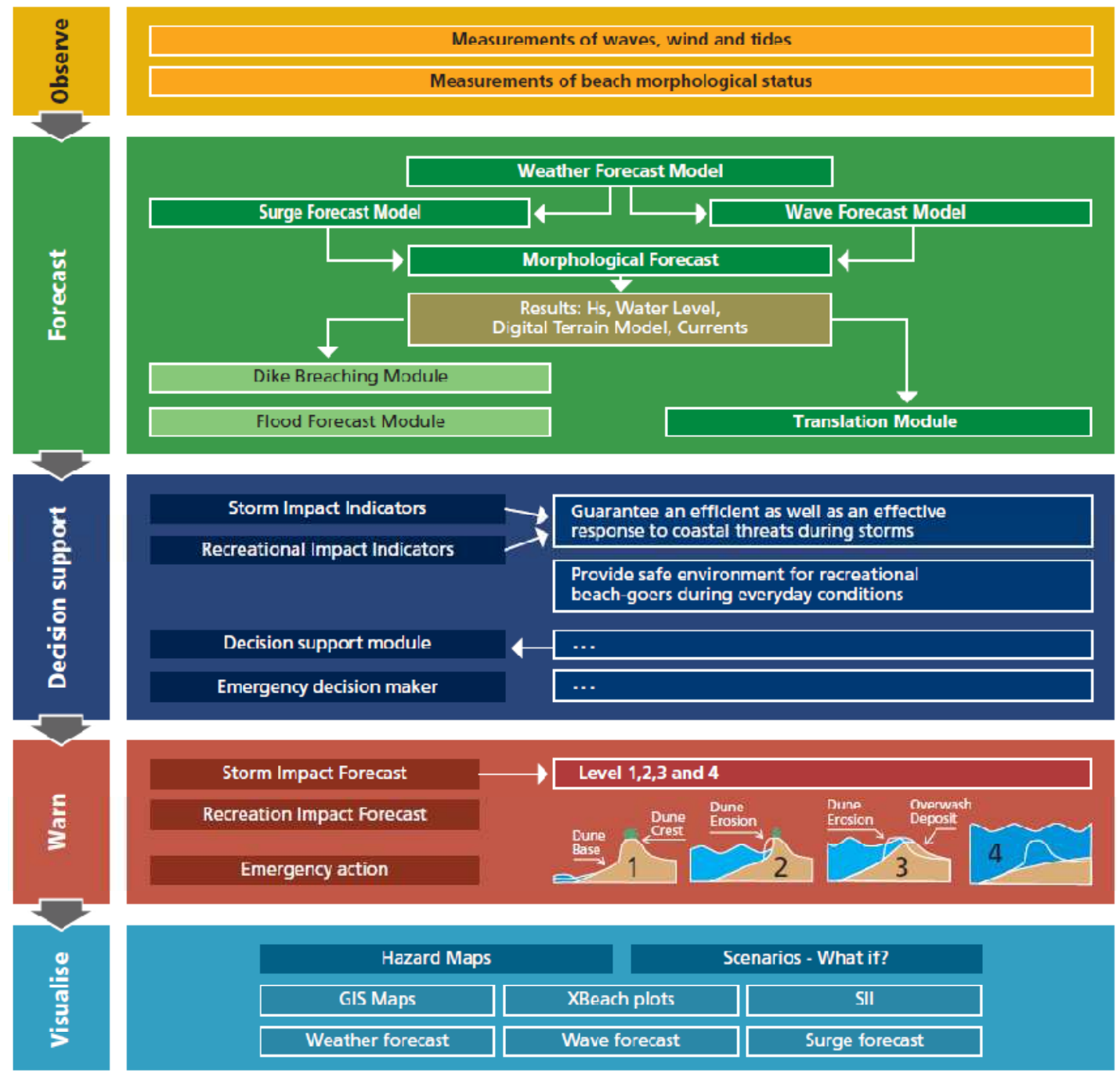

Figure 2 - Generic structure of the Early Warning System for storm impact (CEWS) applied at the different test sites. The Storm Impact Level builds on the scale proposed by Sallenger (2000).

In MICORE the used morphological modelling techniques were based on the open source XBeach model, which has undergone extensive testing at a variety of sites (Roelvink et al. 2009; Van Dongeren et al. 2009a) including a validation for all study sites (Van Dongeren et al. 2009b). As described in Roelvink et al. (2009), the model solves coupled 2DH equations for wave propagation, flow, sediment transport and bottom changes, for varying (spectral) wave and flow boundary conditions. Since each field site represents unique topographic and environmental conditions, this enabled the functionality of the model under various circumstances to be tested for broader use throughout Europe and worldwide.

Examples of results are shown in Figure 3 for the Italian and Bulgarian study sites. For the Italian site, the performance of the model focused on how it simulates dune erosion during storms and for this particular storm event in December 2008 the results show that the post-storm eroded dune face is wellreplicated by the model. The focus in the Bulgarian case was on wave run-up and for the large storm in March 2010 the model results also closely match the measured wave run-up levels.

Important knowledge transfer took place over the course of the project between geoscientists that have knowledge about local and regional coastal conditions and numerical model developers. The end result has ultimately led to a model that has been incorporated in all prototype Early Warning Systems. 

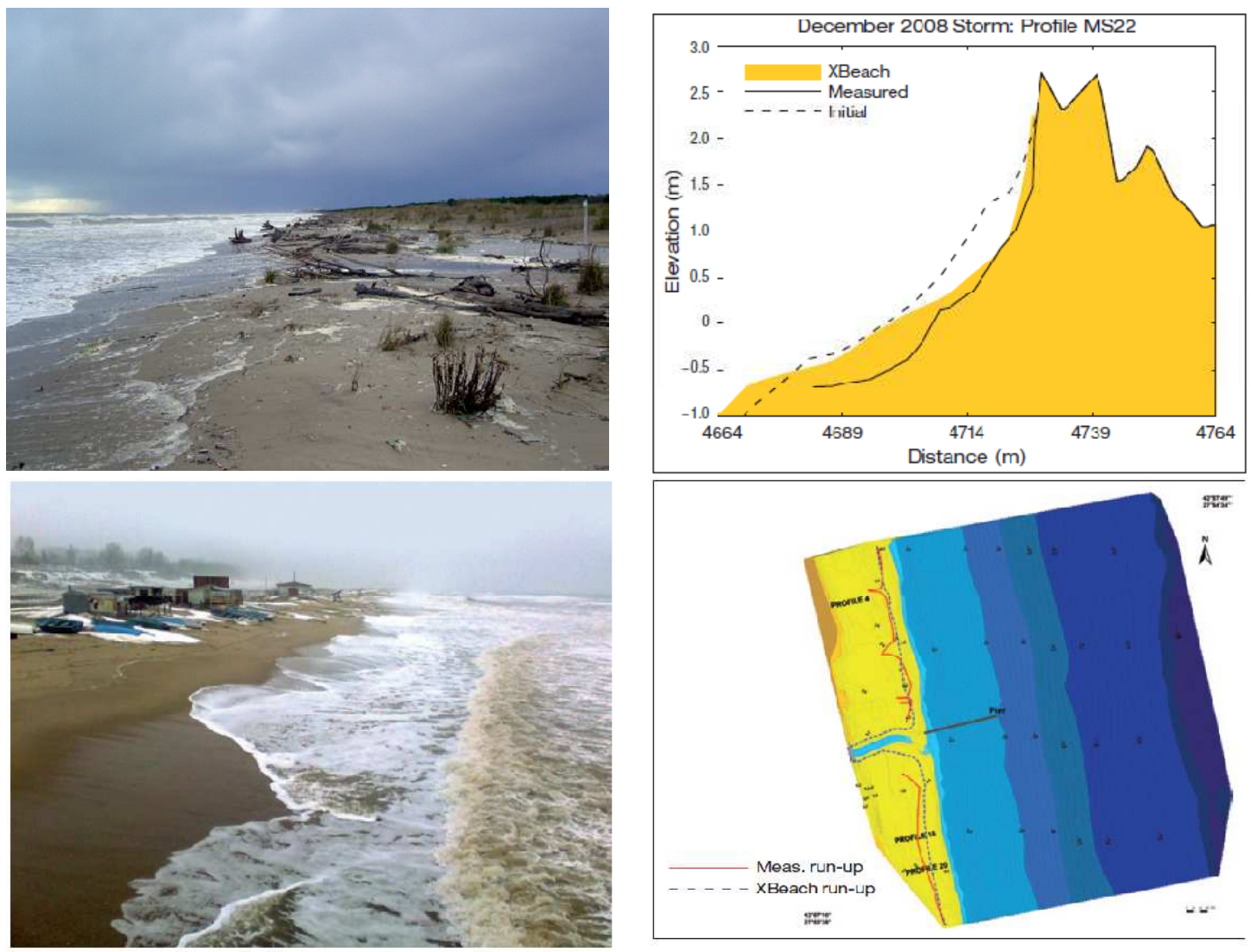

Figure 3 - Upper figures: Lido di Classe, Northern Italy - storm event in December 2008 (left side) and XBeach modelling and validation of dune erosion from that event (Van Dongeren and contributors, 2010). Lower figures: Kamchia Shkorpilovtsi, Bulgaria - wave run-up during a storm event in March 2010 and validation wave run-up estimations using 2D XBeach modelling of the same event (Van Dongeren and contributors, 2010).

\section{STORM IMPACT INDICATORS}

Physical parameters such as dune erosion volumes, flow velocities, wave run-up levels and dyke overtopping discharges are frequently used by coastal experts to quantify the impacts of storm events. From an end-user perspective these parameters are, however, not straight-forward and difficult to be used operationally, where quick decisions have to be made based on the available information.

To translate the quantitative model results in the form of physical parameters to useful information for Civil Protection agencies the Frame of Reference approach (Van Koningsveld et al., 2005, 2007) was used to derive Storm Impact Indicators (SIIs). The Frame of Reference method aims to structure the end user-specialist interaction optimizing the application of the developed knowledge. Effective interaction thereby is needed to prevent or at least defer the seemingly inevitable divergence of the end user's and the specialist's perception on what is relevant knowledge (Van Koningsveld et al., 2003). Applying the method increases the probability that specialist research produces results that are applicable in policy development or practical applications.

Within the MICORE project the Frame of Reference has enhanced the uptake of end user's needs as the driving component for knowledge development, monitoring and CEWS development. The forecast and decision support modules for the Early Warning System therefore focused on delivering output of so-called Storm Impact Indicators (SIIs). SIIs are a quantification of the impact of marine events on the coastal system in a form suitable for decision making. Linked to these SIIs are predefined threshold levels of impact, susceptibility, vulnerability, or risk that trigger various degrees of action by authorities. 
One example of an SII is the Safe beach recreation (Table 1), which is used in the Belgian CEWS as a measure to predict the occurrence of beach scarps. The height of the scarp can be predicted through the CEWS providing a physical parameter, which is translated into an action plan through the Frame of Reference. If storm events create high scarps, then the beaches are unsafe for recreation. In this case the appropriate action is to close the beaches for recreation and to prepare intervention for reshaping the beaches after the storm.

\begin{tabular}{|l|l|l|l|l|l|l|}
\hline \multicolumn{2}{|l|}{ Table 1. Example of SII - Safe beach recreation. } \\
\hline $\begin{array}{l}\text { Strategic } \\
\text { objective }\end{array}$ & $\begin{array}{l}\text { Operational } \\
\text { Objective }\end{array}$ & $\begin{array}{l}\text { Quantitative } \\
\text { State } \\
\text { Concept }\end{array}$ & $\begin{array}{l}\text { Benchmarking } \\
\text { Desired State }\end{array}$ & $\begin{array}{l}\text { Benchmarking } \\
\text { Current State }\end{array}$ & $\begin{array}{l}\text { Intervention } \\
\text { Procedure }\end{array}$ & $\begin{array}{l}\text { Evaluation } \\
\text { Procedure }\end{array}$ \\
\hline $\begin{array}{l}\text { Guarantee } \\
\text { sufficient } \\
\text { safe beach } \\
\text { with a the } \\
\text { smooth } \\
\text { beach } \\
\text { profile for } \\
\text { recreational } \\
\text { use }\end{array}$ & $\begin{array}{l}\text { Keach free } \\
\text { of scarps. } \\
\text { maps with } \\
\text { the } \\
\text { indication of } \\
\text { scarps. }\end{array}$ & $\begin{array}{l}\text { Height of the } \\
\text { scarp }<1 \mathrm{~m} .\end{array}$ & $\begin{array}{l}\text { Model results } \\
\text { for the } \\
\text { position, the } \\
\text { amount and } \\
\text { magnitude of } \\
\text { beach scarps. }\end{array}$ & $\begin{array}{l}\text { Based on the } \\
\text { predicted } \\
\text { beach } \\
\text { profile, close } \\
\text { beaches or } \\
\text { prepare } \\
\text { intervention. }\end{array}$ & $\begin{array}{l}\text { Check } \\
\text { predicted } \\
\text { beach status with } \\
\text { status after } \\
\text { major } \\
\text { storms. }\end{array}$ \\
\hline
\end{tabular}

\section{ONLINE OPERATIONAL EARLY WARNING SYSTEM PROTOTYPES}

The developed prototype CEWSs used a common generic structure (see Figure 2) adaptable to a range of different coastal environments, applied free and open-source software without the need for commercial licenses and tuned the functionalities of the EWS to the end-users needs by using the Frame of Reference approach. For all test sites a demonstration on-line model train was set-up using site-specific or commonly applicable scripts to translate available forecasted input parameters like wind fields and water-level predictions into wave/flow model and morphological model runs. This way the site specific weather forecast input was translated into physical parameters reflecting the morphological impact of the forecasted events, e.g. dune erosion, overtopping and wave run-up. These physical parameters formed the basis for evaluation of the objectives defined within the Frame of Reference, taking into account end-user needs trough predefined SIIs. Based on pre-defined thresholds within the SIIs the model outcome was post-processed and different levels of warnings are issued, distinguishing different impact levels (susceptibility or risk). The warnings are easily visualized using an online web interface, based on open source software like Google Fusion Tables and Google MAPS that can be implemented within almost any existing website maintained by end users.

For each demonstration CEWS was operated in on-line mode, executing this chain of modules and tools (Figure 2) daily. Running the CEWS in daily mode, instead of only during extreme offshore conditions, was found to be crucial in testing the system's robustness and gaining additional confidence by end-users in its overall performance. It also expanded the applicability of the CEWS to more day-today functions such as beach recreational safety, which is reflected in some of the SIIs.

As an illustration of the developed CEWSs the Belgian test case is described more in detail and is accessible through the MICORE website (www.micore.eu). Located in the middle of the Belgian coastline, Ostend is a densely-populated coastal town featuring a wide dissipative beach promenade and numerous apartment blocks built on a dyke protected by a seawall. The CEWS at this site focuses on advising civil protection authorities on the predicted state of four vital SIIS: (i) the width of dry beach available for recreational activities, (ii) the existence and height of potentially-hazardous beach scarps, (iii) the distance between the waterline and vulnerable infrastructures and (iv) the overtopping discharge of any sea water over the dyke as an indication of flood risk to property. For each of these SIIs the model train computes the physical parameters including the morphological feedback loop by applying XBeach (Bolle et. al., 2010) and forecasts three warning levels. The warning levels are visualized by means of color codes on a GOOGLE map (see Figure 4) together with more detailed information related to each of the SIIs (see Figure 4). 

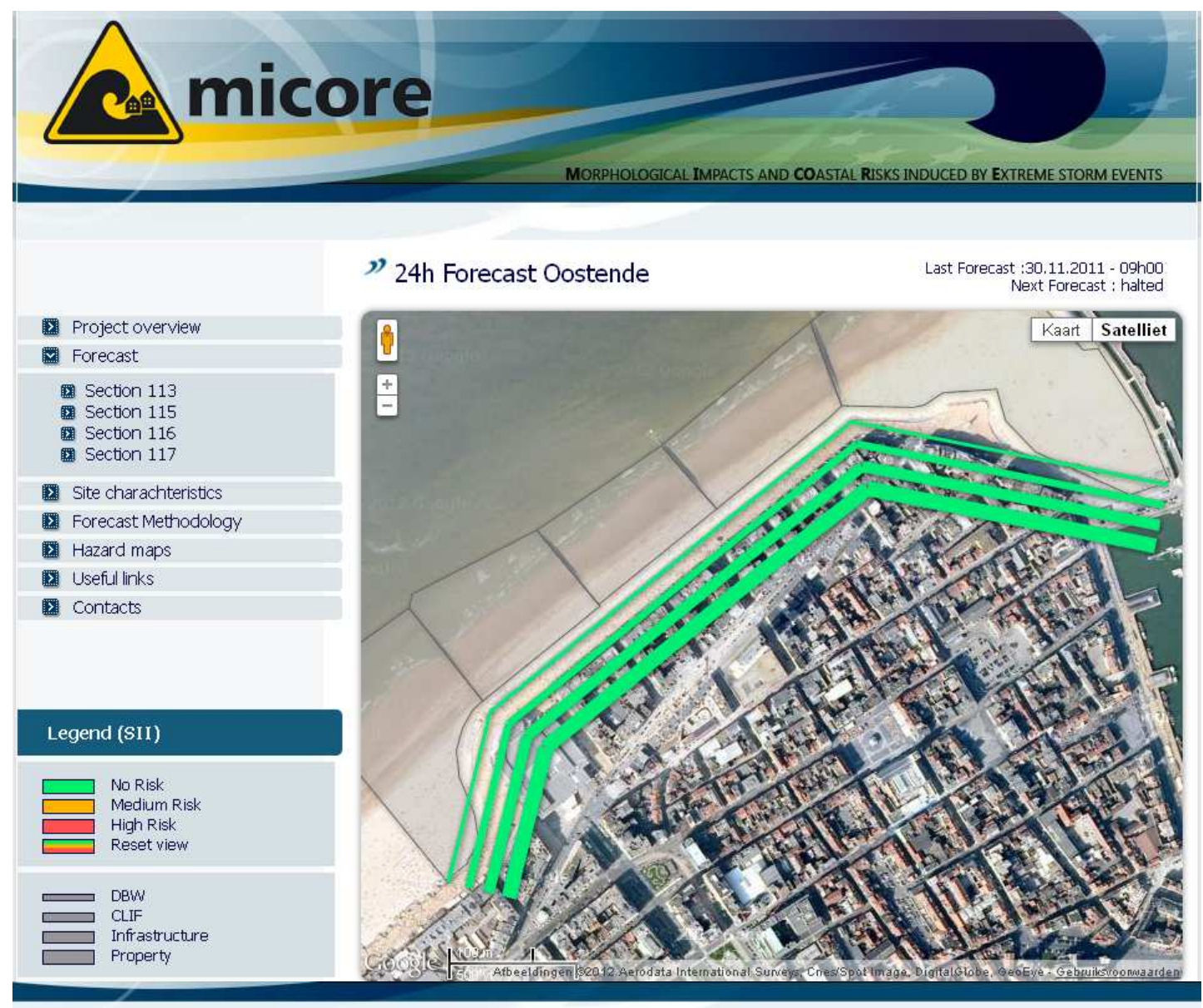

\section{"Forecast Methology}

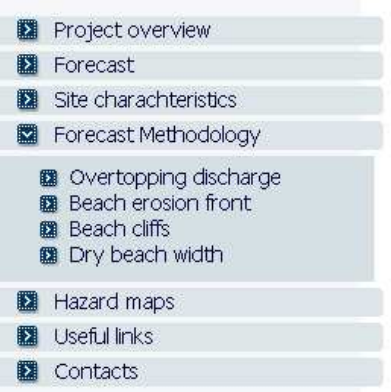

Space for beach recreation - dry beach width DBW

\begin{tabular}{|c|c|c|c|c|c|c|}
\hline $\begin{array}{l}\text { Strategic } \\
\text { objective }\end{array}$ & $\begin{array}{l}\text { Operational } \\
\text { objective }\end{array}$ & QSC & $\begin{array}{l}\text { Benchmarking } \\
\text { desired state }\end{array}$ & $\begin{array}{l}\text { Benchmarking } \\
\text { current state }\end{array}$ & $\begin{array}{l}\text { Intervention } \\
\text { procedure }\end{array}$ & $\begin{array}{l}\text { Evaluation } \\
\text { procedure }\end{array}$ \\
\hline $\begin{array}{l}\text { Provide a } \\
\text { sufficientwide } \\
\text { beach to } \\
\text { ensure } \\
\text { recreational } \\
\text { activities. }\end{array}$ & $\begin{array}{l}\text { Keep the beach } \\
\text { wide enough by } \\
\text { artificial } \\
\text { nourishments } \\
\text { during the low } \\
\text { recreational } \\
\text { season. }\end{array}$ & $\begin{array}{l}\text { Space time } \\
\text { maps with the } \\
\text { position of the } \\
\text { highwater line } \\
\text { and the } \\
\text { remaining dry } \\
\text { beach width. }\end{array}$ & $\begin{array}{l}\text { Dry beach } \\
\text { width }>50-70 \\
\mathrm{~m} \text {, depending } \\
\text { on the local } \\
\text { situation }\end{array}$ & $\begin{array}{l}\text { Model results } \\
\text { for the position } \\
\text { of the high } \\
\text { water line. }\end{array}$ & $\begin{array}{l}\text { Based onthe } \\
\text { predicted dry } \\
\text { beach width } \\
\text { (e.g. after storm } \\
\text { season), } \\
\text { prepare beach } \\
\text { nourishment } \\
\text { campaigns. }\end{array}$ & $\begin{array}{l}\text { After storms } \\
\text { checkifthe } \\
\text { predicted DBW } \\
\text { was accurate } \\
\text { and if change in } \\
\text { nourishment } \\
\text { program is } \\
\text { needed }\end{array}$ \\
\hline
\end{tabular}
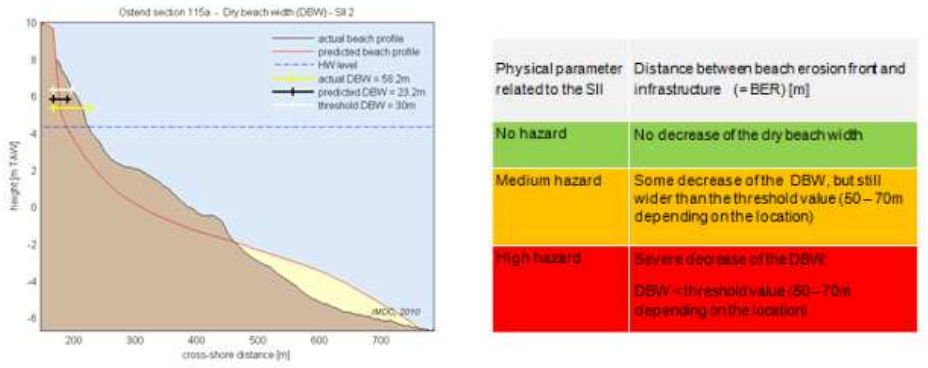

Disclaimer: the information presented on this website is strictly for general divulgation of research objectives and activities. The alert prototype should not be considered as an alert warning and should only be used for scientific purposes. IMDC declines any responsibility on the use of the information presented in all the contents of this website,
well as of any damage or problems derived from using any of the presented information.

Figure 4 - Visualisation of the SII-based CEWS for the Belgian test case at Ostend beach, with detailed information on the Dry Beach Width SIl warnings (www-micore.eu). 


\section{CONCLUSIONS}

The developments performed within the MICORE project have brought significant innovations in the set-up of Early Warning Systems devoted to coastal storm risk, which contribute to improve coastal management and coastal civil protection schemes. The development of nine fully-operational CEWSs for coastal storm risk shows that such an on-line tool based on real-time data acquisition and using a range of state-of-the-art hydrodynamic and morphological open-source models is feasible for vulnerable areas across Europe. These prototype Early Warning Systems can be seen as the foundations for wider applications across Europe and the first step in the forecasting of the impact of marine events on coastal areas.

The MICORE project showed that early involvement, training and exchange of experience between end-users and the scientific community throughout all stages of the development of CEWSs would lead to better customer oriented tools and systems. By doing this, the resulting CEWSs could be more tailor-made to suit the needs of decision makers and therefore more-likely to be adopted as a practical day-to-day tool. An important lesson learned from the applications of the Frame of Reference approach is that information on the physical system is not useful for decision makers per se. It should be supplied in such a form (accurate, reliable as well as sufficiently aggregated) that a decision can be taken based upon it.

The successful application of early warnings is one of the most cost-effective, practical and efficient measures for disaster prevention and the saving of people living in the coastal zone. Considerable progress has been made throughout the set-up of operational prototype CEWSs and in developing the knowledge and technical tools to assess coastal risks. Providing and communicating predictions and warnings should be the results of linking enhanced scientific understanding of natural phenomena to the application of modern information and communication technologies.

Building a fully operational regional EWS is one step forward. The set-up of such a system would require more research and development to provide reliable and proven model coupling techniques, a probabilistic integrated approach and the support of end-users on a national and European level.

\section{ACKNOWLEDGMENTS}

The research leading to these results has received funding from the European Community's Seventh Framework Programme under grant agreement $n^{\circ}$ 202798. All team members from MICORE are acknowledge, particularly the ones involved on XBeach, the Frame of Reference, the Storm Impact Indicators and the CEWS developments.

\section{REFERENCES}

Ciavola, P., Ó. Ferreira, P. Haerens, M. Van Koningsveld, C. Armaroli and Q Lequeux. 2011a. Storm impacts along European coastlines. Part 1: the joint effort of the MICORE and ConHaz projects. Environmental Science and Policy, Elsevier, 14, 912-923.

Ciavola, P., Ó. Ferreira, P. Haerens, M. Van Koningsveld, C. Armaroli. 2011b. Storm impacts along European coastlines. Part2. Lessons learned from the MICORE Project. Environmental Science and Policy, Elsevier, 14, 924-933.

Baart, F., T. van der Kaaij, M. van Ormondt, A. van Dongeren, M. van Koningsveld and J.A. Roelvink. 2009. Real-time forecasting of morphological storm impacts: a case study in the Netherlands. Journal of Coastal Research, SI56, 1617-1621.

Bolle A., P. Mercelis, D. Roelvink, P. Haerens and K. Trouw (2010). 'The application and validation of XBeach for three different field sites', Proceedings of the International Conference on Coastal Engineering, 30 June - 3 July 2010, Shanghai, China.

Sallenger, A.H. 2000. Storm impact scale for barrier islands. Journal of Coastal Research, 16, 890895.

Roelvink, D., A. Reniers, A. van Dongeren, J. van Thiel de Vries, R. McCall and J. Lescinski. 2009. Modeling storm impacts on beaches, dunes and barrier islands. Coastal Engineering, 56, 11331152.

Van Dongeren, A. and contributors, 2010. Validation of dune impact models using European field data. Deliverable 4.1 and 4.2: validation of XBeach and off-the-shelf-models. MICORE project Report. 
Van Dongeren, A., A. Bolle, M. Vousdoukas, T. Plomaritis, P. Eftimova, J. Williams, C. Armaroli, D. Idier, P. Van Geer, J. Van Thiel de Vries, P. Haerens, R. Taborda, J. Benavente, E. Trifonova, P. Ciavola, Y. Balouin and D. Roelvink. 2009a. MICORE: dune erosion and over-wash model validation with data from nine European field sites, Proceedings of Coastal Dynamics 2009: Impacts of Human Activities on Dynamic Coastal Processes, pp. 1-15 (doi:10.1142/9789814282475_0084).

Van Dongeren, A., Bolle, A., Roelvink, J., Vousdoukas, M.I., Plomaritis, T., Williams, J., Armaroli, C., Idier, D., Van Geer, P., Van Thiel de Vries, J., Haerens, P., Taborda, R., Benavente, J., Trifonova, E., Ciavola, P., Balouin, Y. and Eftimova, P. (2009b). Micore: dune erosion and overwash model validation with data from nine European field sites. Proceedings of $A G U$ Conference, San Francisco, EOS Transaction.AGU, 90(52) Fall meet. suppl.; Abstract No NH14A06.

Van Koningsveld, M., M.J.F. Stive, J.P.M Mulder, H.J. de Vriend, D.W. Dunsbergen and B.G. Ruessink. 2003. Usefulness and effectiveness of coastal research. A matter of perception? Journal of Coastal Research, 19, 441-461.

Van Koningsveld, M., M.A. Davidson and D.A. Huntley. 2005. Matching science with coastal management needs; the search for appropriate coastal state indicators. Journal of Coastal Research, 21, 399-411.

Van Koningsveld, M., M.A. Davidson, D.A. Huntley, R. Medina, S.G.J. Aarninkhof, J. Jimenez, J. Ridgewell and A. de Kruif. 2007. A critical review of the CoastView project: recent and future developments in coastal management video systems. Coastal Engineering, 54, 567-576.

United Nations - UNISDR. 2006. Global Survey of Early Warning Systems - An assessment of capacities, gaps and opportunities towards building a comprehensive global early warning system for all natural hazards. 